\title{
Primary Care Clinicians' Views About the Impact of Medicaid Expansion in Michigan: A Mixed Methods Study
}

\author{
Susan Dorr Goold, MD, MHSA, MA ${ }^{7,2,3}$, Renuka Tipirneni, MD, MSc ${ }^{7,2}$, Edith Kieffer, $M P H, P h D^{2,4}$, \\ Adrianne Haggins, MD, $M S^{2,5}$, Cengiz Salman, $M A^{2,6}$, Erica Solway, PhD, MSW, MPH ${ }^{2}$, \\ Lisa Szymecko, PhD, JD7, Tammy Chang, MD, MS ${ }^{2,8}$, Zachary Rowe9, Sarah Clark, MPH 2, 10 , \\ Sunghee Lee, $P h D^{17}$, Eric G. Campbell, $P h D^{12}$, and John Z. Ayanian, MD, MPP 1,2,3,13
}

\begin{abstract}
'Department of Internal Medicine, Medical School, University of Michigan, Ann Arbor, MI, USA; ${ }^{2}$ Institute for Healthcare Policy and Innovation, University of Michigan, Ann Arbor, MI, USA; ${ }^{3}$ Department of Health Management and Policy, School of Public Health, University of Michigan, Ann Arbor, MI, USA; ${ }^{4}$ School of Social Work and the Institute for Healthcare Policy and Innovation, University of Michigan, Ann Arbor, MI, USA;

${ }^{5}$ Emergency Medicine and the Institute for Healthcare Policy and Innovation, University of Michigan, Ann Arbor, MI, USA; ${ }^{6} \mathrm{Center}$ for Bioethics and Social Sciences in Medicine, University of Michigan, Ann Arbor, MI, USA; ${ }^{7}$ Department of Community Psychology, Michigan State University, East Lansing, MI, USA; ${ }^{8}$ Family Medicine, University of Michigan, Ann Arbor, MI, USA; ${ }^{9}$ Friends of Parkside, Detroit, MI, USA; ${ }^{10}$ Department of Pediatrics, University of Michigan, Ann Arbor, MI, USA; ${ }^{11}$ The Institute for Social Research, University of Michigan, Ann Arbor, MI, USA; ${ }^{12} \mathrm{CU}$ Center for Bioethics and Humanities, University of Colorado, Denver, CO, USA; ${ }^{13}$ Gerald R. Ford School of Public Policy, University of Michigan, Ann Arbor, MI, USA.
\end{abstract}

BACKGROUND: Michigan's approach to Medicaid expansion, the Healthy Michigan Plan (HMP), emphasizes primary care, prevention, and incentives for patients and primary care practitioners (PCPs).

OBJECTIVE: Assess PCPs' perspectives about the impact of HMP on their patients and practices.

DESIGN: In 2014-2015, we conducted semi-structured interviews then a statewide survey of PCPs.

SETTING: Interviewees came from varied types of practices in five Michigan regions selected for racial/ethnic diversity and a mix of rural and urban settings. Surveys were sent via mail.

PARTICIPANTS: Interviewees were physician $(n=16)$ and non-physician practitioners $(n=3)$. All Michigan PCPs caring for $\geq 12$ HMP enrollees were surveyed (response rate $55.5 \%, N=2104$ ).

MEASUREMENTS: PCPs' experiences with HMP patients and recent changes in their practices.

RESULTS: Interviews include examples of the impact of Medicaid expansion on patients and practices. A majority of surveyed PCPs reported recent increases in new patients (52.3\%) and patients who had not seen a PCP in many years (56.2\%). For previously uninsured patients, PCPs reported positive impact on control of chronic conditions (74.4\%), early detection of serious illness (71.1\%), medication adherence $(69.1 \%)$, health behaviors $(56.5 \%)$, emotional wellbeing (57.0\%), and the ability to work, attend school, or live independently (41.5\%). HMP patients reportedly still had more difficulty than privately insured patients accessing some services. Most PCPs reported that their practices had, in the past year, hired

Electronic supplementary material The online version of this article (https://doi.org/10.1007/s11606-018-4487-6) contains supplementary material, which is available to authorized users.

Received August 18, 2017

Revised February 21, 2018

Accepted May 4, 2018

Published online June 12, 2018 clinicians (53.2\%) and/or staff (57.5\%); 15.4\% had colocated mental health care. Few (15.8\%) reported established patients' access to urgent appointments worsened.

LIMITATIONS: PCP reports of patient experiences may not be accurate. Results reflect the experiences of PCPs with $\geq 12$ Medicaid patients. Differences between respondents and non-respondents present the possibility for response bias.

CONCLUSIONS: PCPs reported improved patient access to care, medication adherence, chronic condition management, and detection of serious illness. Established patients' access did not diminish, perhaps due to reported practice changes.

J Gen Intern Med 33(8):1307-16

DOI: $10.1007 / \mathrm{s} 11606-018-4487-6$

๑) Society of General Internal Medicine 2018

\section{INTRODUCTION}

Michigan received a Section 1115 waiver from the Centers for Medicare \& Medicaid Services allowing the implementation of an alternative approach to Medicaid expansion under the Affordable Care Act. ${ }^{1}$ Michigan's approach, the Healthy Michigan Plan (HMP), opened enrollment for beneficiaries up to $133 \%$ of the federal poverty level (FPL) in April 2014. During 2017, over 650,000 low-income adults (age 19-64) were enrolled. ${ }^{2}$ HMP covers essential health benefits required by the Affordable Care Act, and benefits such as dental care, home health services, and family planning. Most participants must enroll in a Medicaid managed care plan, either of their own choosing or by assignment if they do not select one.

HMP encourages enrollees to schedule an appointment with a primary care provider (PCP) within 60-90 days of enrollment, though there is no penalty for failing to do so. They can 
choose their own PCP, or one will be assigned to them. During a PCP visit, HMP enrollees are asked to complete a Health Risk Assessment (HRA), which includes questions about health behaviors (e.g., diet, exercise, smoking) and measures of health risk (e.g., blood pressure). The HRA encourages enrollees, in consultation with their PCP, to commit to adopting or maintaining healthy behaviors. Enrollees receive financial incentives such as gift cards or discounted premiums and copayments ${ }^{1}$ if they complete the HRA with their PCP, and it is submitted (faxed) by their PCP to their health plan.

Other features of HMP include copayments for most enrollees, and premium-like monthly contributions for those with incomes between 100 and $133 \%$ of the FPL, up to $2 \%$ of annual income. Annual contributions and copays cannot, in total, exceed $5 \%$ of household income. There are no copays for preventive services or some chronic condition care. Copays and contributions are paid into a special account called the "MI Health Account" rather than at the point of service. Those funds are used to pay for health-related expenses. MI Health Account statements, sent quarterly to enrollees, list health care services received, costs to the beneficiary and the health plan, copays and contributions owed, and payments enrollees remitted. Statements also include information about how to lower their spending, including how to earn health behavior rewards by completing an HRA and committing to a healthy behavior.

This study comprises part of a larger evaluation of the HMP examining the impact of HMP on enrollees from a variety of perspectives. Given the HMP emphasis on primary care, and on health risks and health behaviors, the insights and experiences of PCPs are particularly critical. We asked PCPs to report their experiences with HMP patients, and how they and their practices have adapted and innovated in response to the newly covered population and HMP features.

\section{METHODS}

\section{Individual Interviews}

To design the PCP survey instrument (described below) and to collect qualitative data on physicians' attitudes and experiences with enrollees in the HMP, we conducted 19 semi-structured interviews with PCPs caring for Medicaid/ Healthy Michigan Plan patients between December 2014 and April 2015. Interviews were conducted in five Michigan regions purposefully selected to provide racial/ethnic diversity and a mix of urban and rural communities. Interviewees were both physicians $(n=16)$ and non-physician practitioners working at small private practices, federally qualified health centers (FQHCs), free/low-cost clinics, hospital-based practices, or rural practices. Interviews asked about awareness of patient insurance and experiences caring for HMP patients, including practice changes and the impact of HMP on patients' access to care, management, health, and well-being.

\section{Survey Cohort}

The survey cohort of PCPs was drawn from the 7360 National Provider Identifier (NPI) numbers assigned in the Michigan Department of Health and Human Services (MDHHS) data warehouse for PCPs with at least one HMP managed care enrollee in April 2015. PCPs with at least 12 assigned enrollees were eligible for the survey to assure sufficient contact to be able to respond to questions about their experiences with HMP-covered patients. Practitioners with fewer assigned enrollees $(N=2813)$ were excluded.

Of the 4547 PCPs meeting the initial inclusion criteria, 25 were excluded because the NPI entity code did not reflect an individual physician (20 were organizational NPIs, 4 were deactivated, and 1 was invalid). Further, we excluded 161 physicians with only pediatric specialty because HMP only covers adults, 4 University of Michigan physicians involved in the HMP evaluation, and 35 physicians with out-of-state addresses $>30 \mathrm{mi}$ from the Michigan border. After exclusions, 4322 primary care practitioners ( 3686 physicians and 636 nurse practitioners/physician assistants) remained in the cohort.

\section{Survey Design}

The survey included measures drawn from prior national surveys of PCP and practice characteristics ${ }^{3-5}$ and PCP experiences and perceptions on a variety of topics. New items specific to HMP were developed from PCP interviews and cognitively tested with a physician from a low-cost clinic and a physician assistant from a private practice. Items measured knowledge of patient insurance status; understanding of HMP's key features; changes in practice; new practice approaches adopted within the previous year; experiences caring for newly insured Medicaid/HMP patients, including ability to access specialty care, equipment, medications, dental care, and mental health care $^{6}$; perceptions of whether HMP enrollees and privately insured patients had difficulty accessing care $^{7}$; and perceptions of the impact of HMP on previously uninsured patients.

\section{Survey Administration}

The survey was mailed in June 2015 and included a personalized cover letter describing the project and the confidentiality of responses, an HMP fact sheet, a paper survey, a $\$ 20$ bill, and a postage-paid return envelope. The fact sheet outlined HMP eligibility and key program features to help respondents differentiate between HMP and traditional Medicaid coverage. The cover letter also gave information on how to complete the survey online. Follow-up mailings were sent to any nonrespondents in August and September 2015.

\section{Analysis}

We calculated descriptive statistics such as the proportion of PCPs reporting an impact of HMP on control of chronic conditions for previously uninsured patients. To compare 
responses by PCPs to questions about access to care for HMP vs. privately insured patients, we first used paired $t$ tests to compare the proportion responding "do not know." We then used Wilcoxon signed-rank tests to compare often/sometimes/ rarely/never responses to access questions for HMP vs. privately insured patients, excluding PCPs who answered do not know to either question (see Fig. 1). To test for response bias on the basis of familiarity with Medicaid/HMP, we performed these same analyses for two subgroups: those reporting Medicaid/HMP as their practice's predominant payer type and those who agreed or strongly agreed "I know what kind of insurance a patient has at the beginning of an encounter." Results were similar for those subgroups with the exception of a smaller proportion of do not know responses.

Bivariate and multivariable logistic regression analysis assessed the association of independent variables (personal, professional, and practice characteristics) with dependent variables - practice changes and experiences reported since Medicaid expansion. We ran all multivariate models with and without interaction variables when associations were found between independent variables (ownership $\times$ practice size, and $\mathrm{FQHC} \times$ predominant payer type), using chi-squared goodness-of-fit tests to assess model fit. When goodness of fit did not improve with interaction variables, they were removed from the model. All analyses were performed using STATA version 14 (Stata Corp, College Station, TX).

Semi-structured interviews were recorded, transcribed, and coded iteratively by two or more researchers using grounded theory and standard qualitative analysis techniques ${ }^{8,9}$ using Dedoose $\odot$ software.

This project was deemed exempt by IRBs at the University of Michigan and the Michigan Department of Health and Human Services as a government-mandated evaluation of a public program.

\section{RESULTS}

\section{Characteristics of Interviewed PCPs}

Three PCP interviewees were non-physicians. Fourteen of 16 physicians specialized in family medicine $(88 \%)$ and 2 in internal medicine (12\%). Five interviewees had less than 10 , six $10-20$, and eight more than 20 years in practice. Five worked in FQHCs, three in large, hospital-based practices, two in a free or low-cost clinic, seven in a small private practice, and two in rural health clinics.

\section{Characteristics of Survey Respondents}

Of the original sample of 4322 PCPs, 501 mailed surveys were returned as undeliverable and considered ineligible (Appendix Fig. 1). Of the remaining $3821 \mathrm{PCPs}, 27$ were ineligible (e.g., retired, moved out of state) and 2104 responded (1986 mail, 118 online). The final response rate was $55.5 \%$ (54.2\% for physicians, $65.4 \%$ for nurse practitioners/physician assistants)

Comparison of the 2104 respondents and the 1690 nonrespondents (Appendix Table A1) revealed no significant differences in gender, birth year, number of affiliated Medicaid managed care plans, or practice in an FQHC. Non-respondents were more likely to be internal medicine physicians. Respondents were more likely than non-respondents to have a rural practice address and be located in the Upper Peninsula, northwest, or northeast regions of the state (see Table A1, Appendix).

Just over half of respondents (55.4\%) were men and 79.3\% self-identified as white (Table 1). Among respondents, $83.2 \%$ were physicians, although $71.7 \%$ had non-physician providers in their practice. About half identified their specialty as family medicine $(53.4 \%)$ and a quarter $(24.1 \%)$ as internal medicine. More than half $(57.5 \%)$ were in practices with five or fewer providers; $14.9 \%$ practiced in FQHCs. Three quarters of PCP respondents $(75.3 \%)$ practiced in urban settings, including $31.2 \%$ in the Detroit region. About one third (36.0\%) reported Medicaid/HMP as the predominant payer.

\section{Knowledge of Patients' Insurance}

Just over half of PCPs (53.4\%) reported knowing what kind of insurance a patient had at the beginning of an encounter, and nearly all $(90.6 \%)$ reported they could easily find out a patient's insurance status. About a third (34.9\%) reported not paying attention to a patient's insurance status while $40.2 \%$ reported only finding out about a patient's insurance if they have trouble getting a recommended health service.

\section{Impact on Patients}

Most PCPs reported that HMP had a positive impact (great or some impact vs. little or no impact) on health, health care, and function for previously uninsured patients (Table 2). More than two thirds of PCPs said that HMP had positive impact on better control of chronic conditions (74.4\%), early detection of serious illness $(71.1 \%)$, and improved medication adherence $(69.1 \%)$. Over half reported positive impact on improved health behaviors $(56.5 \%)$ and emotional wellbeing $(57.0 \%)$, while $46.1 \%$ reported positive impact on ability to work or attend school and $41.5 \%$ on ability to live independently. In interviews, PCPs described how HMP allowed them to diagnose multiple conditions in new patients and helped newly insured existing patients meet many unmet needs. They reported that HMP helped patients adhere to recommended medical treatment, improve health behaviors, and reduce financial worries. Many noted the impact of HMP on working poor patients who previously lacked insurance. (see Appendix Table A2 for more examples).

A 64-year-old gentleman who... upon receiving health insurance... he pursued care and that was his first... 


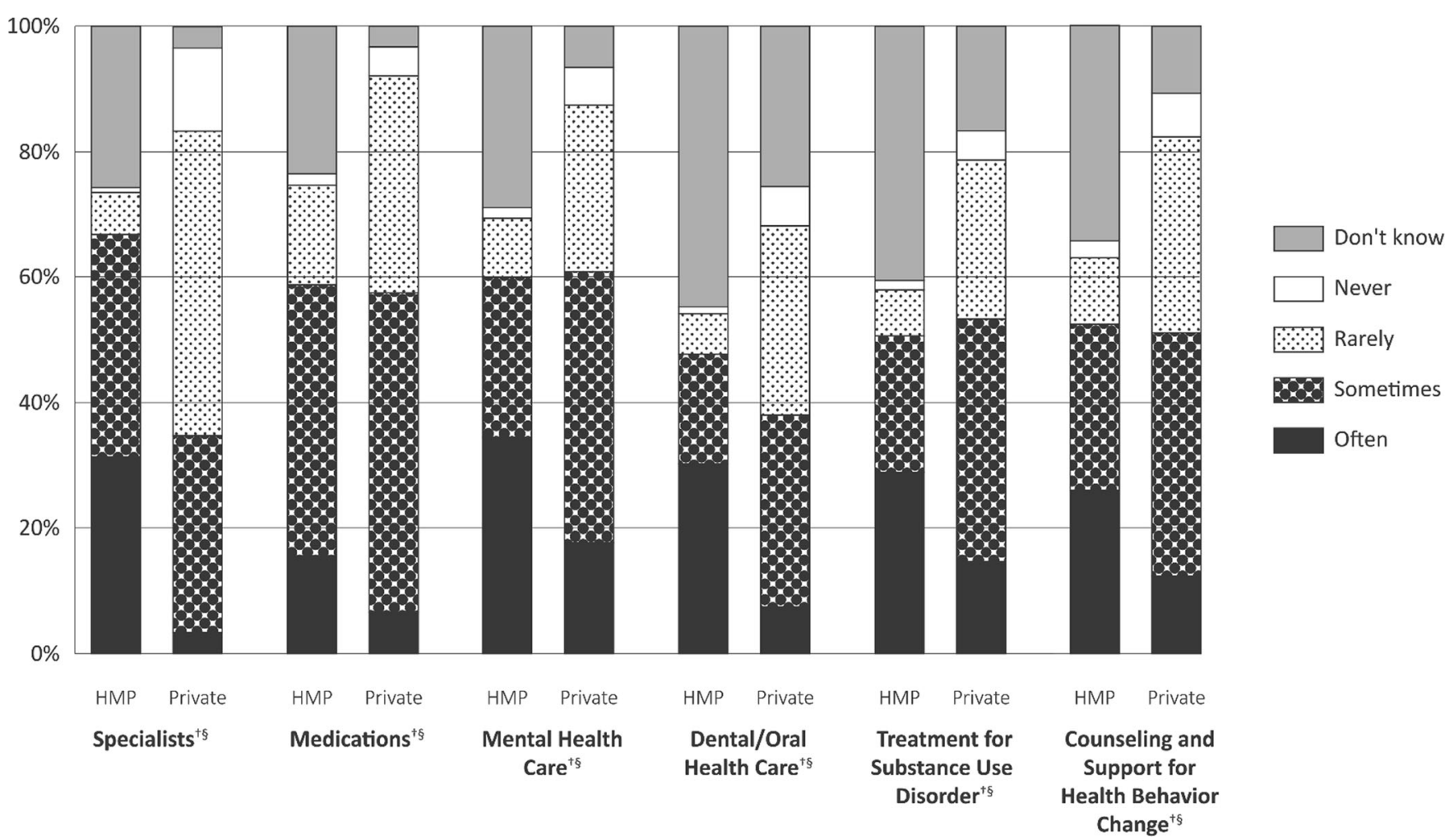

Figure 1 PCP reports of difficulty accessing care for Healthy Michigan Plan and privately insured patients. PCP responses to two questions: How often do your Healthy Michigan Plan patients have difficulty accessing the following? How often do your privately insured patients have difficulty accessing the following? ${ }^{\S} p<0.001$ Wilcoxon signed-rank test comparing often/sometimes/rarely/never responses by PCPs to these paired questions. PCPs who answered do not know to either question were excluded from analysis. ${ }^{\dagger} p<0.001$ paired $t$ test comparing do not know responses to these paired questions.

physical evaluation of any sort in 40 years. He was found to be hypertensive and diabetic and ... at that initial visit for an eye exam, given his hypertension, he was found to have ...hemianopia, which was ... caused by a prior stroke (Urban, FQHC)

Some are existing patients that now have insurance, and so now they can get the things done you had been wanting them to do, but I would say I've seen several that didn't have a doctor for years. They knew they had diabetes and other problems.,. They had no health insurance, and so they just ignored it for years. Now they're coming in and getting established. (Urban physician; Small, private practice)

So we see a lot of people with asthma, and a number of patients who, you know, are just kind of eking by on borrowed medications...now we're able to get inhalers for them and do a pulmonary function test and start working on improving things instead of just damage control.
(Rural physician; Large, hospital-based practice)

We have so many working poor people up here... they work two and three jobs, barely can scrape it together, and they're coming in after years of little or no care... they are getting everything done...It's like problems that have backed up over the years. Dental stuff is being taken care of. Vision is being taken care of, but they usually start with me, and it's been really wonderful. (Rural physician assistant, Rural health clinic)

They are no longer petrified about, "Oh, I can't afford that," or "I can't do that." (Urban physician, FQHC)

PCPs reported both improved access to health care for those previously uninsured, and sometimes difficulty, when compared to those with private insurance, accessing specialists, medications, mental health care, dental care, treatment for substance use, and counseling for behavior change (Fig. 1 and Appendix Table A3). In interviews, PCPs gave examples both of improved access and difficulty accessing specialists, 
Table 1 Personal, Professional, and Practice Characteristics of PCP Respondents $(N=2104)$

\begin{tabular}{|c|c|c|c|c|c|}
\hline Personal characteristics & $N$ & & $\%$ & & \\
\hline \multicolumn{6}{|l|}{ Gender } \\
\hline Male & \multirow{2}{*}{\multicolumn{2}{|c|}{$\begin{array}{l}1165 \\
939\end{array}$}} & \multicolumn{2}{|l|}{55.4} & \\
\hline Female & & & 44.6 & & \\
\hline \multicolumn{6}{|l|}{ Race } \\
\hline White & \multicolumn{2}{|l|}{1583} & \multicolumn{2}{|l|}{79.3} & \\
\hline Black/African-American & \multicolumn{2}{|l|}{93} & \multicolumn{3}{|l|}{4.7} \\
\hline Asian/Pacific Islander & \multicolumn{2}{|l|}{224} & \multicolumn{3}{|l|}{11.2} \\
\hline American Indian/Alaska Native & \multicolumn{2}{|l|}{10} & 0.5 & & \\
\hline Other & 86 & & 4.3 & & \\
\hline Ethnicity $^{3}$ & & & & & \\
\hline Hispanic/Latino & 46 & & 2.3 & & \\
\hline Non-Hispanic/Latino & 1978 & & 97.7 & & \\
\hline Professional characteristics & $N$ & & $\%$ & & \\
\hline Provider type & & & & & \\
\hline Physician & 1750 & & 83.2 & & \\
\hline Non-physician (NP/PA) & 357 & & 16.8 & & \\
\hline Specialty & & & & & \\
\hline Family medicine & 1123 & & 53.4 & & \\
\hline Internal medicine & 507 & & 24.1 & & \\
\hline Medicine-pediatrics & 67 & & 3.2 & & \\
\hline General practice (GP) & 24 & & 1.1 & & \\
\hline Obstetrics/gynecology (OB/Gyn) & 12 & & 0.6 & & \\
\hline Nurse practitioner (NP) & 192 & & 9.1 & & \\
\hline Physician's assistant (PA) & 165 & & 7.8 & & \\
\hline Other & 14 & & 0.7 & & \\
\hline Board/specialty certification & & & & & \\
\hline Yes & 1695 & & 81.6 & & \\
\hline No & 383 & & 18.4 & & \\
\hline Years in practice & & & & & \\
\hline$<10$ years & 520 & & 25.9 & & \\
\hline $10-20$ years & 676 & & 33.7 & & \\
\hline$>20$ years & 810 & & 40.4 & & \\
\hline Provider ownership of practice & & & & & \\
\hline Full owner & 446 & & 22.0 & & \\
\hline Partner/part owner & 232 & & 11.4 & & \\
\hline Employee & 1352 & & 66.6 & & \\
\hline Practice characteristics & $N$ & & $\%$ & & \\
\hline Practice size (mean, median, SD) & $7.5,5,16.5$ & & & & \\
\hline Small ( $\leq 5$ practitioners)* & 1157 & & 57.5 & & \\
\hline Large ( $\geq 6$ practitioners $)$ & 855 & & 42.5 & & \\
\hline Presence of non-physician practitioners in practice $^{\dagger}$ & 1275 & & 71.7 & & \\
\hline Practice type ${ }^{\ddagger}$ & & & & & \\
\hline Federally qualified health center (FQHC) & 311 & & 14.9 & & \\
\hline University/teaching hospital practice & 276 & & 13.1 & & \\
\hline Hospital-based practice (non-teaching) & 643 & & 30.7 & & \\
\hline Payer mix (current $\%$ of patients with insurance type) & Mean \% & & SD & & \\
\hline Private & $32.8 \%$ & & 19.8 & & \\
\hline Medicaid & $23.3 \%$ & & 18.3 & & \\
\hline Healthy Michigan Plan & $10.9 \%$ & & 11.8 & & \\
\hline Medicare & $30.2 \%$ & & 16.7 & & \\
\hline Uninsured & $5.8 \%$ & & 7.1 & & \\
\hline Predominant payer $\operatorname{mix}^{\S}$ & $\mathrm{N}$ & & $\%$ & & \\
\hline Private & 522 & & 27.4 & & \\
\hline Medicaid/Healthy Michigan Plan & 686 & & 36.0 & & \\
\hline Medicare & 645 & & 33.9 & & \\
\hline Uninsured & 15 & & 0.8 & & \\
\hline Mixed & 37 & & 1.9 & & \\
\hline Payment arrangement & & & & & \\
\hline Fee for service & 784 & & 37.5 & & \\
\hline Salary & 946 & & 45.3 & & \\
\hline Capitation & 44 & & 2.1 & & \\
\hline Mixed & 275 & & 13.2 & & \\
\hline Other & 40 & & 1.9 & & \\
\hline Urbanicity" & & & & & \\
\hline Urban & 1584 & & 75.3 & & \\
\hline Suburban & 193 & & 9.2 & & \\
\hline Rural & 327 & & 15.5 & & \\
\hline Familiarity with patients' insurance & $\begin{array}{l}\text { Strongly agree } \\
N(\%)\end{array}$ & $\begin{array}{l}\text { Agree } \\
N(\%)\end{array}$ & $\begin{array}{l}\text { Neither } \\
N(\%)\end{array}$ & $\begin{array}{l}\text { Disagree } \\
N(\%)\end{array}$ & $\begin{array}{l}\text { Strongly disagree } \\
N(\%)\end{array}$ \\
\hline If I need to know a patient's insurance status it is & $904(43.4)$ & $982(47.2)$ & $131(6.3)$ & $57(2.7)$ & $7(0.3)$ \\
\hline $\begin{array}{l}\text { easy to find out }(n=2081) \\
\text { I know what kind of insurance a patient has at the } \\
\text { beginning of an encounter }(n=2081)\end{array}$ & $442(21.2)$ & $671(32.2)$ & $342(16.4)$ & $427(20.5)$ & 199 (9.6) \\
\hline
\end{tabular}


Table 1. (continued)

\begin{tabular}{|c|c|c|c|c|c|}
\hline Personal characteristics & $N$ & & $\%$ & & \\
\hline $\begin{array}{l}\text { I ignore a patient's insurance status on purpose so it does } \\
\text { not affect my recommendations }(n=2078)\end{array}$ & $294(14.1)$ & $433(20.8)$ & $549(26.4)$ & $577(27.8)$ & $225(10.8)$ \\
\hline $\begin{array}{l}\text { I only find out about a patient's insurance coverage if they } \\
\text { have trouble getting something I recommend }(n=2071)\end{array}$ & $281(13.6)$ & $551(26.6)$ & $393(19.0)$ & $649(31.3)$ & $197(9.5)$ \\
\hline
\end{tabular}

*Dichotomized at sample median

$>5 \%$ missing

${ }^{t}$ Practice types do not add to $100 \%$ as respondents chose options from a non-exhaustive list

${ }^{\xi}$ Composite variable of all current payers: payer is considered predominant for the practice if $>30 \%$ of physician's patients have this payer type and $<$ $30 \%$ of patients have any other payer type. "Mixed" includes practices with more than one payer representing $>30 \%$ of patients, or practices with < $30 \%$ of patients for each payer type

"Zip codes and county codes were linked to the US Department of Agriculture Economic Research Service 2013 Urban Influence Codes to classify regions into urban (codes 1-2), suburban (codes 3-7), and rural (codes 8-12) designations

dental care, mental health care, prescriptions, and interventions to address health behaviors. Sometimes they described the lack of available specialists in rural areas. In some cases, they talked about the challenge of finding certain types of providers who would accept Medicaid (Appendix Table A2).

Specialists - If they have no insurance versus they have Medicaid or Healthy Michigan Medicaid, again, there's just a world of difference because now I can get stuff done. You know, back in the day, we never used to order colonoscopies for patients if they were uninsured because nobody can afford \$2,000 to have that done. But with Medicaid where that's a covered benefit, yeah, now we get to order them all the time on people. (Urban physician, Free/low-cost clinic)

If the patient needs a prescription and it's for a simple condition like depression, we can certainly co-manage with them. But when we're dealing with more complex psychiatric illnesses, we do need these patients to be referred on to a psychiatrist, and at that point we have had problems with the patients not always having access to behavioral health, because many of the Medicaid plans, part of Healthy Michigan, are not accepted by the behavioral health department in our health system. (Urban physician; Large, hospital-based practice)

Dermatology is a huge issue... In this county we have a huge problem because we have no place to send our Medicaid patients. And obviously they can't afford to do it out of pocket. (Rural health center)

\section{Impact on Practice}

New Patients and Newly Insured Patients. Interviewed PCPs described an influx of new patients (Appendix Table A2). Over half of survey respondents reported that their practice had seen an increase in the number of new patients since April $2014(52.3 \%)$ and increased numbers of new patients who had not seen a PCP in many years $(56.2 \%$ ) (Table 3 ). Half of PCPs $(50.6 \%)$ reported that their practice had existing patients who had been uninsured gaining insurance from HMP. Fewer (31.6\%) reported patients changing from other insurance to HMP; those with predominantly Medicaid payer mix and rural practices were more likely to report this. FQHCs, and those with predominantly uninsured, Medicaid and mixed payer mixes and suburban practices, were more likely to report an increase in new patients. FQHCs, and those with predominantly Medicaid payer mix, were more likely to report existing patients who had been uninsured gained

Table 2 Impact of Healthy Michigan Plan on Previously Uninsured Patients

\begin{tabular}{|c|c|c|c|c|c|}
\hline $\begin{array}{l}\text { Please think about what has changed for your patients } \\
\text { who were previously uninsured and are now covered } \\
\text { by the Healthy Michigan Plan. Rate the extent to } \\
\text { which you think the Healthy Michigan Plan has had } \\
\text { an impact on each of the following for these patients: }\end{array}$ & Great impact & Some impact & Little impact & No impact & Do not know \\
\hline Better control of chron & $701(35.0 \%)$ & $789(39.4 \%)$ & $139(6.9 \%)$ & $30(1.5 \%)$ & $346(17.3 \%)$ \\
\hline Early detection of serious illness & $674(33.7 \%)$ & $748(37.4 \%)$ & $153(7.6 \%)$ & $40(2.0 \%)$ & $387(19.3 \%)$ \\
\hline Improved medication adherence & $568(28.3 \%)$ & $817(40.8 \%)$ & $215(10.7 \%)$ & $54(2.7 \%)$ & $350(17.5 \%)$ \\
\hline Improved health behaviors & $323(16.1 \%)$ & $811(40.4 \%)$ & $378(18.9 \%)$ & $106(5.3 \%)$ & $387(19.3 \%)$ \\
\hline Better ability to work or attend school & $263(13.1 \%)$ & $661(33.0 \%)$ & $399(19.9 \%)$ & $114(5.7 \%)$ & $566(28.3 \%)$ \\
\hline Improved emotional well-being & $328(16.4 \%)$ & $813(40.6 \%)$ & $348(17.4 \%)$ & $76(3.8 \%)$ & $439(21.9 \%)$ \\
\hline Improved ability to live independently & $239(11.9 \%)$ & $593(29.6 \%)$ & $438(21.9 \%)$ & $141(7.0 \%)$ & $591(29.5 \%)$ \\
\hline
\end{tabular}


Table 3 Adjusted Proportions of Primary Care Providers Reporting Medical Practice Changes Since the Launch of the Healthy Michigan Plan

\begin{tabular}{|c|c|c|c|c|c|c|c|c|c|}
\hline & \multicolumn{4}{|c|}{$\begin{array}{l}\text { To what extent has your practice experienced the } \\
\text { following since the Healthy Michigan Plan began in } \\
\text { April 2014?* }\end{array}$} & \multicolumn{5}{|c|}{ Has your practice made the following changes in the past year? } \\
\hline & $\begin{array}{l}\text { Increase } \\
\text { number } \\
\text { of new } \\
\text { patients }\end{array}$ & $\begin{array}{l}\text { Existing } \\
\text { patients } \\
\text { who had } \\
\text { been } \\
\text { uninsured } \\
\text { or self-pay } \\
\text { gained in- } \\
\text { surance }\end{array}$ & $\begin{array}{l}\text { Existing } \\
\text { patients } \\
\text { changed } \\
\text { from other } \\
\text { insurance } \\
\text { to Healthy } \\
\text { Michigan } \\
\text { Plan }\end{array}$ & $\begin{array}{l}\text { Increase in } \\
\text { the number of } \\
\text { new patients } \\
\text { who have not } \\
\text { seen a } \\
\text { primary care } \\
\text { practitioner in } \\
\text { many years }\end{array}$ & $\begin{array}{l}\text { Hired } \\
\text { additional } \\
\text { clinicians }\end{array}$ & $\begin{array}{l}\text { Hired } \\
\text { additional } \\
\text { office staff }\end{array}$ & $\begin{array}{l}\text { Consulted } \\
\text { with care } \\
\text { coordinator, } \\
\text { case manager, } \\
\text { or community } \\
\text { health worker }\end{array}$ & $\begin{array}{l}\text { Changed } \\
\text { workflow } \\
\text { processes } \\
\text { for new } \\
\text { patients }\end{array}$ & $\begin{array}{l}\text { Colocated } \\
\text { mental } \\
\text { health } \\
\text { within } \\
\text { primary } \\
\text { care }\end{array}$ \\
\hline All & $52.3 \%$ & $50.6 \%$ & $31.6 \%$ & $56.2 \%$ & $53.2 \%$ & $57.5 \%$ & $55.8 \%$ & $41.7 \%$ & $15.4 \%$ \\
\hline $\begin{array}{l}\text { Practice size } \\
\text { Large } \\
\text { (ref) }\end{array}$ & $51.4 \%$ & $50.0 \%$ & $28.9 \%$ & $54.0 \%$ & $71.8 \%$ & $67.8 \%$ & $68.2 \%$ & $49.0 \%$ & $18.3 \%$ \\
\hline $\begin{array}{l}\text { Small } \\
\text { Practice type }\end{array}$ & $51.7 \%$ & $51.2 \%$ & $31.9 \%$ & $57.8 \%$ & $40.0 \% \S$ & $52.6 \% \S$ & $51.9 \% \S$ & $38.5 \% \S$ & $12.2 \% \S$ \\
\hline $\begin{array}{l}\mathrm{FQHC} \\
\text { (ref) }\end{array}$ & $58.8 \%$ & $64.9 \%$ & $32.6 \%$ & $63.7 \%$ & $62.4 \%$ & $70.0 \%$ & $72.6 \%$ & $44.2 \%$ & $29.9 \%$ \\
\hline $\begin{array}{l}\text { Non- } \\
\text { FQHC }\end{array}$ & $50.5 \%{ }^{\dagger}$ & $48.5 \%{ }^{\S}$ & $30.3 \%$ & $55.1 \%^{\dagger}$ & $52.1 \%^{\dagger}$ & $57.1 \%$ & $56.1 \% \S$ & $42.8 \%$ & $11.8 \%^{\S}$ \\
\hline $\begin{array}{l}\text { Academic } \\
\text { (ref) }\end{array}$ & $52.9 \%$ & $53.5 \%$ & $29.9 \%$ & $59.2 \%$ & $49.2 \%$ & $51.6 \%$ & $52.1 \%$ & $39.6 \%$ & $13.9 \%$ \\
\hline $\begin{array}{l}\text { Non- } \\
\text { academic }\end{array}$ & $51.3 \%$ & $50.2 \%$ & $30.8 \%$ & $55.7 \%$ & $54.3 \%$ & $60.1 \%$ & $59.3 \%$ & $43.5 \%$ & $15.6 \%$ \\
\hline $\begin{array}{l}\text { Hospital- } \\
\text { based (ref) }\end{array}$ & $51.5 \%$ & $49.5 \%$ & $28.3 \%$ & $56.9 \%$ & $51.6 \%$ & $59.3 \%$ & $55.1 \%$ & $42.8 \%$ & $11.2 \%$ \\
\hline $\begin{array}{l}\text { Not } \\
\text { hospital- } \\
\text { based }\end{array}$ & $51.6 \%$ & $51.3 \%$ & $31.7 \%$ & $55.8 \%$ & $54.6 \%$ & $58.8 \%$ & $59.9 \%$ & $43.1 \%$ & $17.8 \%$ \\
\hline \multicolumn{10}{|c|}{ Predominant payer mix } \\
\hline $\begin{array}{l}\text { Private } \\
\text { (ref) }\end{array}$ & $39.4 \%$ & $41.5 \%$ & $22.4 \%$ & $46.2 \%$ & $54.8 \%$ & $60.0 \%$ & $62.3 \%$ & $40.7 \%$ & $11.0 \%$ \\
\hline Medicare & $43.8 \%$ & $44.8 \%$ & $25.0 \%$ & $50.5 \%$ & $50.9 \%$ & $58.8 \%$ & $55.8 \%{ }^{\star}$ & $48.5 \%{ }^{\dagger}$ & $13.1 \%$ \\
\hline Medicaid & $69.7 \%^{\S}$ & $64.7 \% §$ & $43.0 \% \S$ & $72.4 \% \%^{\S}$ & $53.2 \%$ & $60.1 \%$ & $55.5 \%{ }^{\S}$ & $44.0 \%$ & $19.7 \%^{\S}$ \\
\hline Uninsured & $79.4 \%$ & $59.1 \%$ & $14.4 \%$ & $61.5 \%$ & $40.9 \%$ & $34.5 \%$ & $68.3 \%$ & $40.5 \%$ & $29.1 \%$ \\
\hline Mixed & $49.9 \%^{\dagger}$ & $50.4 \%$ & $29.2 \%$ & $49.7 \%$ & $57.6 \%$ & $51.6 \%^{\dagger}$ & $59.9 \%^{\dagger}$ & $35.1 \%$ & $15.3 \%$ \\
\hline \multicolumn{10}{|l|}{ MiPCT } \\
\hline Yes & - & - & - & - & $52.8 \%$ & $60.0 \%$ & $78.0 \% \S$ & $44.4 \%$ & $22.0 \%$ \\
\hline No & - & - & - & - & $53.8 \%$ & $58.6 \%$ & $52.3 \%$ & $42.5 \%$ & $13.1 \%$ \\
\hline \multicolumn{10}{|l|}{ Urbanicity } \\
\hline $\begin{array}{l}\text { Urban } \\
\text { (ref) }\end{array}$ & $51.0 \%$ & $49.5 \%$ & $28.6 \%$ & $56.7 \%$ & $53.6 \%$ & $60.0 \%$ & $58.1 \%$ & $41.5 \%$ & $13.6 \%$ \\
\hline Suburban & $59.8 \%^{\dagger}$ & $55.6 \%$ & $33.1 \%$ & $60.3 \%$ & $52.6 \%$ & $50.5 \%^{\dagger}$ & $53.3 \%$ & $45.5 \%$ & $14.8 \%$ \\
\hline Rural & $49.1 \%$ & $53.7 \%$ & $38.8 \%$ & $51.3 \%$ & $53.9 \%$ & $58.9 \%$ & $62.2 \%$ & $48.3 \%^{\dagger}$ & $23.6 \%$ \\
\hline
\end{tabular}

Proportions are the predictive margins from logistic regression models adjusted for each practice characteristic in the table, as well as PCP gender, specialty, ownership of practice, and years in practice. MiPCT indicates participation in the Michigan Primary Care Transformation (MiPCT) Project, a 3-year, multi-payer, state-wide project aimed at reforming primary care payment models and expanding the capabilities of patient-centered medical homes (PCMH) throughout the state. Analysis was done using Stata 14. All p values are based on logistic regression analysis

*Analyses based on sum of those who responded "to a great extent" or "to some extent" for the items below

${ }_{p}<0.05$

$p<0.01$

$s_{p}<0.001$

insurance, and an increase in the number of patients who had not seen a PCP in many years. Despite this increase in new patients, only $15.8 \%$ reported a decrease in same- or next-day availability for established patients. In contrast, some interviewed physicians reported difficulties accommodating urgent appointments, or the need for HMP enrollees to see a PCP within the first 90 days (Appendix Table A2).

The idea of a huge wave of people knocking on the door saying, "We need our first exam in three months," ... It was overwhelming. (Rural physician, $\mathrm{FQHC}$ )
We're sort of overrun and the house is full. So, we're still open. Any Healthy Michigan patient can call us and come see us, but it's not like you're going to probably get as timely care as would be ideal. (Urban physician, FQHC).

Changes in Practice Design. Interviewees reported hiring staff not only to meet increases in patients and maintain appointment availability but also to handle referrals and prior authorizations. They also reported newly hired clinicians, working with case managers and community health workers and increasing the availability of same-day appointments and 
extended hours. Those who related experiences with mental health colocation spoke of the advantage of easier access to mental health care.

So organization-wide. . Thirty-nine persons have been slotted for new employment...it's about an 8 or $10 \%$ staff addition as a result of Healthy Michigan. (Urban physician, $\mathrm{FQHC}$ )

That [co-location] has been very helpful especially to our Medicaid patients ...we can get those people in quickly and get treatment, which was otherwise very difficult. ...now it's less of a barrier for them to get behavioral health services. (Rural physician; Small, private practice)

There are more PA's at our clinic than there used to be. (Rural physician; Large, hospital-based practice)

So we had to hire...create a position for somebody to basically find out who takes Medicaid and arrange for those referrals, as well as process those prior authorizations for various tests. (Rural physician; Small, private practice)

Most survey respondents also reported that practices had hired clinicians and/or staff in the past year (53.2\%) (Table 3). Large and FQHC practices were more likely to have hired new clinicians in the past year. Small, non-FQHC, academic, and suburban practices were less likely to report hiring staff. Over half of PCPs (55.8\%) reported consulting with care coordinators, case managers, and/or community health workers in the past year. Large and FQHC practices and those with predominantly private or uninsured payer mixes were all more likely to report doing so. Approximately $15.4 \%$ of PCPs reported having newly colocated mental health services in their practices during the past year. Large, FQHC, those with predominantly Medicaid payer mix, and rural practices were more likely to report this change to their practice.

\section{DISCUSSION}

In this comprehensive, mixed methods study, PCPs in Michigan, as in other states ${ }^{10,11}$, reported improved abilities to detect and manage chronic conditions such as diabetes and hypertension in patients who gained coverage due to Medicaid expansion, and better patient adherence to medical regimens. Most PCPs also reported that the HMP helped patients improve health behaviors and emotional well-being, and improved their ability to work, attend school, or live independently. In interviews, PCPs described previously uninsured patients for whom they had identified serious illness early; survey results confirmed these are relatively frequent experiences reported by PCPs.

Our findings confirm and expand previous work demonstrating decreased rates of uninsurance, improved coverage, and increased utilization rates after Medicaid expansion. ${ }^{12-15}$ Other studies have linked Medicaid expansion with improved self-reported health status, increase in the probability of diagnosis of chronic disease, lower rates of depression, and reduced financial strain. ${ }^{10,11}$ PCP interviews provide rich, powerful examples of the unmet needs of those newly insured through Medicaid expansion, and survey respondents reported positive impact on access, adherence, and health. Improved access to care, preventive service use, and health behaviors found in expansion states ${ }^{16}$ were also reported, in surveys and interviews, by PCPs in Michigan. Comparisons of Medicaid enrollees to low-income uninsured persons have found greater awareness and control of chronic diseases, while many studies show delayed diagnosis and worse management of chronic diseases for the uninsured. ${ }^{17-19}$

Like other studies, ${ }^{20,21}$ PCPs reported an increase in new patients, including some who had not sought primary care in many years. They reported hiring clinicians and staff, changing workflow for new patients, colocating mental health care in primary care, and hiring or consulting with care coordinators, case managers, and community health workers. Perhaps due to those changes, few reported that established patients' access to same- or next-day appointments worsened. Tipirneni et al., using a simulated patient approach, found the availability of primary care appointments improved for new Medicaid patients in the first months after HMP implementation ${ }^{22}$ and that, over the year following implementation, median wait times remained stable for new Medicaid patients while the proportion of appointments scheduled with non-physician providers increased for both Medicaid and privately insured patients. ${ }^{23}$ Polsky et al. found early evidence that increased Medicaid reimbursement to primary care providers, as mandated in the ACA, was associated with improved appointment availability for Medicaid enrollees among participating providers, without generating longer waiting times, ${ }^{24}$ and later found appointment availability persisted despite the end of the Medicaid primary rate increase. ${ }^{25}$ The increase in new patients without an impact on same or next-day appointments is similar to results from the Kaiser Family Foundation survey assessing PCP experiences with, and attitudes about, Medicaid expansion that found a lack of perceived impact on quality of care or patient satisfaction. ${ }^{26}$

According to PCPs, while access to care improved greatly for previously uninsured patients, access to some services (e.g., specialty care, mental health care) sometimes remained challenging for enrollees and their PCPs, and lagged behind 
reported access for those with private insurance. Such disparities have been noted for Medicaid patients before and after the ACA, particularly for specialty and mental health care. For instance, before the ACA, Medicaid enrollees in Colorado were more likely than both privately insured and uninsured persons to report difficulty getting an appointment with a doctor. ${ }^{27}$ Also before the ACA, community health center directors reported more difficulty accessing specialty care for those with Medicaid coverage than for those with private insurance, but less difficulty than for those without any insurance. Medicaid enrollees may have more difficulty obtaining appointments with specialists. ${ }^{28}$ While they are more likely to receive outpatient or inpatient mental health care, ${ }^{29}$ the prevalence of mental illness is higher in Medicaid enrollees than in the privately insured or uninsured. ${ }^{30} \mathrm{~A}$ review of delivery systems and access after Medicaid expansion in four states reported difficulty accessing behavioral health care and treatment for substance use disorder. ${ }^{31,32}$ As one of our interviewed physicians said, "It's kind of a mess. But I don't blame Medicaid expansion for that. It was a mess before then."

As with all surveys, results based on self-report should be interpreted with some caution. Self-reports of PCPs' own behavior and practice can suffer from recall and/or social desirability bias. Practice changes may not be due solely to Medicaid expansion; they could, for instance, reflect changes for other newly insured due to the ACA. ${ }^{33}$ The accuracy of physician reports about their patients' experiences may vary with what is being reported. Estimates of patient quality of life, for instance, are not usually accurate, ${ }^{34}$ but reports about appointment availability are generally more accurate. Primary care physician reports about access, practice changes, and challenges, and quality tends to be trustworthy. The Commonwealth Fund's international surveys of primary care physicians demonstrate the utility of PCPs' unique insights for policymakers. ${ }^{35}$ The substantial portion of PCP respondents in our survey who responded do not know to questions about access shows the limits of their ability to report. However, PCPs are uniquely able to share experiences from the "front lines" of health system change and thus provide valuable information about how those changes are playing out for patients. This is especially true for Medicaid expansion that emphasizes primary care, disease prevention, and management and less use of acute care. Since we surveyed only PCPs caring for 12 or more HMP enrollees, results should not be generalized to PCPs with fewer (or no) Medicaid patients. Differences between respondents and non-respondents also present the possibility for response bias. The experiences of PCPs in rural areas, for instance, appeared to differ from other practice locations.

Our survey results, and the more detailed accounts from interviews, suggest that Medicaid expansion emphasizing primary care, health risk assessment, and prevention has improved access to preventive services, and detection and management of chronic conditions. According to primary care providers, uninsured patients gaining Medicaid coverage gained access to services for many previously unmet needs and improved well-being, ability to work or attend school, and live independently. While each state's expansion could be considered unique, the focus, in Michigan, on primary care and addressing health risks presents important lessons for other states considering whether and how to expand their Medicaid programs.

Corresponding Author: Susan Dorr Goold, MD, MHSA, MA; Department of Internal Medicine, Medical School University of Michigan, 2800 Plymouth Road, 425W, Ann Arbor, MI 48109, USA (e-mail: sgoold@umich.edu).

\section{Compliance with ethical standards:}

Conflict of interest: The authors declare that they do not have a conflict of interest.

\section{REFERENCES}

1. Ayanian JZ. Michigan's approach to Medicaid expansion and reform. N Engl J Med 2013;369:1773-1775.

2. Healthy Michigan Plan. Michigan Department of Health and Human Services. 2017. Accessed at http://www.michigan.gov/mdhhs/0,5885,7339-71547_2943_66797-,00.html on 3 March 2018.

3. Friedberg MW, Chen PG, Van Busum KR, Aunon F, Pham C, Caloyeras $\mathbf{J}$, et al. Factors affecting physician professional satisfaction and their implications for patient care, health systems, and health policy. Santa Monica, CA: RAND Corporation, 2013. Report No.: RR-439-AMA

4. U.S. Department of Health and Human Services, Centers for Disease Control and Prevention, National Center for Health Statistics. National Ambulatory Medical Care Survey 2014 Panel. 2014. Accessed at http:// www.cdc.gov/nchs/data/ahcd/2014_NAMCS_Physician_Induction_ Sample_Card.pdf on 30 March 2018.

5. Newman SE, Udow-Phillips M, and Anderson KC. 2012 Michigan Physician Survey. Ann Arbor, MI: Center for Healthcare Research and Transformation, 2010.

6. SteelFisher GK, Blendon RJ, Sussman T, Connolly JM, Benson JM, Herrmann MJ. Physicians' views of the Massachusetts health care reform law-a poll. N Engl J Med 2009; 361:e39.

7. The Commonwealth Fund. 2012 International Survey of Primary Care Doctors. 2012. Accessed at http://www.commonwealthfund.org/ /media/files/surveys/2012/41083-ihp-2012-questionnaire21712-finalus3contact-1.pdf on March 30, 2018.

8. Patton MQ. How to use qualitative methods in evaluation. Newbury Park, CA: Sage, 1987.

9. Strauss A and Corbin J. Basics of qualitative research: grounded theory procedures and techniques. 3rd ed. Newbury Park, CA: Sage, 2008.

10. Sommers BD, Blendon RJ, Orav EJ, Epstein AM. Changes in utilization and health among low-income adults after Medicaid expansion or expanded private insurance. JAMA Intern Med 2016; 176:1501-1509.

11. Kaufman H, Chen Z, Fonseca V, McPhaul MJ. Surge in newly identified diabetes among Medicaid patients in 2014 within expansion states under the Affordable Care Act. Diabetes Care 2015; 38:833.

12. Baicker K, Taubman SL, Allen HL, et al. The Oregon Experiment-effects of Medicaid on clinical outcomes. N Engl J Med 2013; 368:1713-1722.

13. Sommers B, Blendon R, Orav EJ. Both the 'private option' and traditional Medicaid expansions improved access to care for low-income adults. Health Aff 2016; 35:96-105.

14. Wherry LR, Miller S. Early coverage, access, utilization, and health effects associated with the Affordable Care Act Medicaid expansions. JAMA Intern Med 2016; 164:795-803.

15. Miller S, Wherry LR. Health and access to care during the first 2 years of the ACA Medicaid expansions. New Engl J Med 2017; 376:947-956.

16. Simon K, Soni A, Cawley J. The impact of health insurance on preventive care and health behaviors: evidence from the first two years of the ACA Medicaid expansions. J Pol Anal Manag 2017; 36:390-417.

17. Christopher AS, McCormick D, Woolhandler S, Himmelstein DU, Bor DH, Wilper AP. Access to care and chronic disease outcomes among 
medicaid-insured persons versus the uninsured. Am J Public Health 2016; 106:63-69.

18. Decker SL, Kostova D, Kenney GM, Long SK. Health status, risk factors, and medical conditions among persons enrolled in Medicaid vs uninsured low-income adults potentially eligible for Medicaid under the Affordable Care Act. JAMA 2013; 309:2579-2586.

19. Piette JD, Wagner TH, Potter MB, Schillinger D. Health insurance status, cost-related medication underuse, and outcomes among diabetes patients in three systems of care. Med Care 2004; 42:102-109.

20. Gray J, Sung I, Richardson S. Observations on the Affordable Care Act: 2014. athenaResearch and Robert Wood Johnson Foundation ACA View Report. 2015 Feb 25. Accessed at http://www.athenahealth.com/ /media/athenaweb/files/pdf/acaview_year_end_2014.pdf on March 30, 2018.

21. Gray J, Zink A, Drevfus T. Effects of the Affordable Care Act through 2015. athenaResearch and Robert Wood Johnson Foundation ACA View Report. 2016 March 1. Accessed at http://www.athenahealth.com/ /media/athenaweb/files/pdf/acaview_tracking_the_impact_of_health_ care_reform on March 30, 2018.

22. Tipirneni R, Rhodes KV, Hayward RA, Lichtenstein RL, Reamer EN, Davis MM. Primary care appointment availability for new Medicaid patients increased after Medicaid expansion in Michigan. Health Aff 2015; 34:10-377.

23. Tipirneni R, Rhodes KV, Hayward RA, et al. Primary care appointment availability and nonphysician providers one year after Medicaid expansion. Am J Manag Care 2016; 22:427-431.

24. Polsky D, Richards M, Basseyn S, et al. Appointment availability after increases in Medicaid payments for primary care. N Engl J Med 2015; 372:537-545.

25. Polsky D, Candon M, Saloner B et al. Changes in primary care access between 2012 and 2016 for new patients with Medicaid and private coverage. JAMA Intern Med 2017; 177:588-590.

26. Experiences and attitudes of primary care providers under the first year of ACA coverage expansion. Henry J. Kaiser Family Foundation. 2016 June 18. Accessed at https://kaiserfamilyfoundation.files.wordpress. com/2015/06/experiences-and-attitudes-of-primary-care-providers-under-the-first-year-of-aca-coverage-expansion.pdf on March 30, 2018.
27. The Colorado Trust. Medicaid in Colorado: how enrollees access and use health care. Colorado Health Access Survey (CHAS) Issue Brief. 2011 Data Series: 5 .

28. Asplin BR, Rhodes KV, Levy H, Lurie N, Crain AL, Carlin BP, Kellermann AL. Insurance status and access to urgent ambulatory care follow-up appointments. JAMA 2005; 294:1248-1254.

29. Facilitating access to mental health services: a look at Medicaid, private insurance, and the uninsured. The Henry J. Kaiser Family Foundation. 2017 Nov. 27. Accessed at https://www.kff.org/medicaid/fact-sheet/ facilitating-access-to-mental-health-services-a-look-at-medicaid-privateinsurance-and-the-uninsured/ on March 30, 2018.

30. Cook NL, Hicks LS, O'Malley AJ, Keegan T, Guadagnoli E, Landon BE. Access to specialty care and medical services in community health centers. Health Aff 2007; 26:1459-1468.

31. Atiga S, Rudowitz R, Tolbert J, Paradise J, Majerol M. Findings from the field: Medicaid delivery systems and access to care in four states in year three of the ACA. The Henry J. Kaiser Family Foundation. 2016 Sept. 20. Accessed at https://www.kff.org/medicaid/issue-brief/findings-from-the-field-medicaid-delivery-systems-and-access-to-care-infour-states-in-year-three-of-the-aca/ on March 30, 2018.

32. Antonisse L, Garfield R, Rudowitz R, Artiga S. The effects of Medicaid expansion under the ACA: findings from a literature review. The Henry J. Kaiser Family Foundation. 2016 June 20. Accessed at https://www.kff. org/report-section/the-effects-of-medicaid-expansion-under-the-acafindings-from-a-literature-review-issue-brief/ on March 30, 2018.

33. Cohen RA, Martinez ME, Zammitti EP. Health insurance coverage: early release of estimates from the National Health Interview Survey, 2015. Hyattsville, MD: National Center for Health Statistics. 2017 May. Accessed at https://www.cdc.gov/nchs/data/nhis/earlyrelease/ insur201605.pdf on March. 30, 2018.

34. Slevin ML, Plant H, Lynch DA, Drinkwater J, Gregory WM. Who should measure quality of life, the doctor or the patient? $\mathrm{Br} \mathrm{J}$ Cancer 1988;57:109-112.

35. Osborn R, Moulds D, Schneider EC, Doty MM, Squires D, Sarnak Do. Primary care physicians in ten countries report challenges caring for patients with complex health needs. Health Aff 2015; 34:2104-2112. 